\title{
Análise ambiental e problemas socioambientais na porção leste do Mato Grosso do Sul, sob a ótica de dados secundários e de noticiários (1980 2020)
}

Environmental analysis and socio-environmental problems in the eastern portion of Mato Grosso do Sul, from the perspective of secondary data and news (1980-2020)

Análisis ambiental y problemas socioambientales en la parte oriental de Mato Grosso do Sul, desde la perspectiva de datos secundarios y noticias (19802020)

\author{
Arlinda Montalvão de Oliveira \\ Doutoranda, UFMS, Brasil. \\ arlinda_moliver@hotmail.com
}

Ana Fábia Damasceno Silva Brunet Doutoranda, UFMS, Brasil. anafabiabrunet@hotmail.com

Mário Marcio Germiniano Mestrando, UFMS, Brasil. mario_marcio12@hotmail.com 


\title{
RESUMO
}

Os municípios localizados na fronteira Leste do Estado de Mato Grosso do Sul, compreendendo Três Lagoas, Água Clara e Ribas do Rio Pardo, vivenciaram nas últimas décadas uma revolução em suas atividades econômicas, da pecuária extensiva para o plantio de eucalipto, levando o Estado de Mato Grosso do Sul ao ranking nacional na produção de celulose. A presente pesquisa propõe: a análise de conteúdos, material obtido com recortes de matérias publicadas em jornais e sites de noticiário on-line, sobre a produção do eucalipto e celulose no município de Três Lagoas, local onde estão instaladas as fábricas Eldorado Brasil e da Fibria/Suzano; e analisar o novo modelo de economia capitalista, apresentando os pontos positivos e negativos para os municípios produtores e áreas adjacentes. A análise dos dados da presente pesquisa perpassa a década de 1980 até os dias atuais, período em que registrou o ápice na mudança da atividade econômica da pecuária extensiva (predominante do município de Três Lagoas) para a produção de celulose. A base epistemológica está apoiada na concepção dos estudos de Lacey sobre o papel da Ciência e seus valores sociais e morais. Nota-se que o apogeu da economia, voltada para a silvicultura apresentou benefícios e impactos causados pelas atividades econômicas, expondo os benefícios das inovações tecnológicas empregadas no setor agroindustrial e revelando os impactos socioambientais, decorrentes do plantio de eucalipto e da produção de celulose.

PALAVRAS-CHAVE: Agroindústria. Silvicultura. Meio ambiente.

\begin{abstract}
The municipalities located on the eastern border of the State of Mato Grosso do Sul, comprising Três Lagoas, Água Clara and Ribas do Rio Pardo, it have experienced in the last decades a revolution in their economic activities, from extensive livestock to eucalyptus planting, leading the State of Mato Grosso do Sul to the national ranking in cellulose production. This research proposes: content analysis, material obtained from clippings of articles published in newspapers and online news sites, on the production of eucalyptus and cellulose in the municipality of Três Lagoas, where the Eldorado Brasil and Fibria / Suzano are; analyze the new model of capitalist economy, presenting the positive and negative points for the producing municipalities and adjacent areas. The analysis of the data in the present research spans the 1980s to the present day, a period in which the peak in the change in economic activity from extensive livestock (predominant in the municipality of Três Lagoas) to pulp production was recorded. The epistemological basis is supported by the conception of Lacey's studies on the role of Science and its social and moral values. Note if, the heyday of the economy focused on forestry punctuates the benefits and impacts caused by economic activities, exposing the benefits of technological innovations employed in the agro-industrial sector and revealing the socio-environmental impacts resulting from eucalyptus planting and cellulose production.
\end{abstract}

KEYWORDS: Agribusiness. Forestry. Environment.

\section{RESUMEN}

Los municipios ubicados en la frontera oriental del estado de Mato Grosso do Sul, que comprenden Três Lagoas, Água Clara y Ribas do Rio Pardo, han experimentado en las últimas décadas una revolución en sus actividades económicas, desde la ganadería extensiva hasta la plantación de eucaliptos, liderando el estado de Mato Grosso do Sul a la clasificación nacional en la producción de celulosa. Esta investigación propone: análisis de contenido, material obtenido de recortes de artículos publicados en periódicos y sitios de noticias en línea, sobre la producción de eucalipto y celulosa en el municipio de Três Lagoas, donde se encuentra Eldorado Brasil y Fibria / Suzano; analizar el nuevo modelo de economía capitalista, presentando los puntos positivos y negativos para los municipios productores y las áreas adyacentes. El análisis de los datos en la presente investigación abarca desde la década de 1980 hasta la actualidad, un período en el que se registró el pico en el cambio en la actividad económica de la ganadería extensiva (predominante en el municipio de Três Lagoas) a la producción de pulpa. La base epistemológica se apoya en la concepción de los estudios de Lacey sobre el papel de la ciencia y sus valores sociales y morales. Nota si, el apogeo de la economía centrada en la silvicultura puntúa los beneficios e impactos causados por las actividades económicas, exponiendo los beneficios de las innovaciones tecnológicas empleadas en el sector agroindustrial y desmitificando los impactos socioambientales resultantes de la plantación de eucalipto y la producción de celulosa.

PALABRAS CLAVE: Agronegocios. Silvicultura. Medio ambiente. 


\section{INTRODUÇÃO}

As transformações do ambiente natural para o rural na porção Leste do Estado do Mato Grosso do Sul tiveram início com a pecuária extensiva, contribuindo para o desenvolvimento da Região Centro-Oeste, representando as primeiras alterações significativas do território estudado. 0 processo de reflorestamento de eucalipto iniciou na Costa Leste, na década de 1980, primeiramente no município de Água Clara e posteriormente nos municípios de Três Lagoas e Ribas do Rio Pardo, com o apoio do Poder Público, propondo incentivos fiscais, propiciando a instalação de grandes empresas reflorestadoras na região.

O estado de Mato Grosso do Sul sempre apresentou amplas potencialidades territoriais e climáticas, favorecendo a expansão e desenvolvimento de suas atividades econômicas. Com destaque para as atividades da agropecuária, como a pecuária extensiva e a extração vegetal (madeira). As condições favoráveis do clima, a disponibilidade de grande extensão de áreas de pastagens para o plantio de eucalipto e o acesso às fontes de energia elétrica e gás natural representaram valorosos atrativos para criação e ampliação do parque industrial e agroindustrial no Setor Secundário, tornando favoráveis as instalações de pequenas, médias e grandes empresas comerciais, promovendo também o crescimento do Setor Terciário.

O presente estudo está embasado na análise de recortes de matérias publicadas em jornais, revistas e notícias divulgadas em sites, como apresentada na Revista Globo Rural por Kiss (2011): "Plantações de Eucalipto desbancam pecuária de corte em Mato Grosso do Sul". Observa-se que quase sempre as mídias divulgam os benefícios econômicos e sociais oportunizados pelas grandes empresas, dificilmente apontam os problemas sociais e ambientais (impactos na biodiversidade) causados pela atividade econômica.

A base epistemológica de análise das matérias publicadas nos diferentes meios de comunicação, apontados nesta pesquisa está, ancorada nas propostas de Lacey (2010). Em seus estudos, a construção da ciência é epistêmica deve ser desenvolvida para o bem-estar social, com a aplicação de empreendimentos científicos e estratégias para atender a sociedade. Porém, a ciência não é livre de valores, com os pressupostos de imparcialidade, neutralidade e autonomia, que podem ser realizáveis ou não realizáveis, de forma harmoniosa entre os diferentes interesses do setor econômico, das necessidades sociais e de maneira racional de uso e exploração dos recursos do meio ambiente.

Nesse sentido, o presente estudo apresenta as principais causas e consequências das transformações ambientais em áreas favoráveis e destinadas ao plantio de eucalipto e aponta considerações sobre o posicionamento da população, que é composta por valores epistêmicos, valores sociais, pessoais, morais e outros - definindo, assim, sua relação socioeconômica e socioambiental local. 


\section{OBJETIVOS}

Desse modo, a finalidade desta pesquisa teve como princípio identificar os valores sociais e conhecer os pontos positivos e negativos, divulgados por meios de comunicações locais, em relação aos principais problemas ambientais decorrentes do plantio de eucalipto para produção de celulose nos municípios localizados na Região da Costa Leste, do Estado do Mato Grosso do Sul.

\section{METODOLOGIA}

A área escolhida para a pesquisa apresentou grande desenvolvimento econômico nas três últimas décadas, com a expansão da silvicultura, conceituada como reflorestamento o plantio de eucalipto para abastecer as fábricas de papel e celulose do município de Três Lagoas/MS.

A presente pesquisa propôs-se a recortes de notícias publicadas on-line, sobre o avanço do plantio de eucalipto em áreas e municípios localizados na região da Costa Leste do estado de Mato Grosso do Sul. O recorte temporal foi delimitado partir da década de 1980, até os dias atuais, década de 2020. Período marcado pelo desenvolvimento econômico significativo da região, baseado na pecuária extensiva, no plantio de eucalipto e na construção das duas fábricas destinadas a produção de celulose para fabricação e exportação de papel.

Utilizando como metodologia a análise de dados quantitativos, também denominada análise do conteúdo que, segundo Morais (1999), faz-se necessário seguir três etapas essenciais para sistematização da pesquisa, sendo: categorização, descrição e a interpretação dos dados.

Conforme Morais (1999) a Análise de Conteúdo é uma metodologia utilizada para análise, descrição e interpretação de documentos e textos, tendo como objetivo principal apresentar características qualitativa ou quantitativa dos fatos pesquisados. Seguindo esse modelo de análise foi possível conceber a análise dos conteúdos estudados e presente neste texto, respeitando as três etapas.

Primeiramente realizou-se a categorização das informações, promovendo o agrupamento dos dados disponíveis em noticiários online e considerados semelhantes entre si, divulgados com de temas de interesse comuns, previamente estabelecidos e relacionados aos objetivos apresentados nessa pesquisa. Podendo assim, enfatizar a relação social e ambiental decorrentes do plantio de eucalipto par produção de celulose na porção leste do estado de Mato Grosso do Sul.

$\mathrm{Na}$ segunda etapa da descrição buscou-se em gabinete localizar e elaborar o mapa com a identificação e localização dos municípios que cultivam eucalipto. A seguir realizaram-se três saídas de campo para registrar a realidade dos dados levantados em laboratório. Desse modo, foi possível registrar em imagem fotográfica a realidade da área estudada. Com essas informações em mãos foi possível elaborar o mapa e o texto descritivo composto no corpo deste documento.

Por fim, a terceira etapa realizou-se a interpretação e análise dos conteúdos obtidos a partir de fundamentos teóricos metodológicos estudados e aqui apresentados. Assim a presente pesquisa está amparada em dados quantitativos e posteriormente relacionada aos de natureza 
qualitativa.

\title{
MÉTODO DE ANÁLISE
}

A base epistemológica está ancorada em Lacey (2010), em sua Tese I, que pressupõe a imparcialidade, a neutralidade e a autonomia da pesquisa científica, porém, a aplicabilidade da ciência não está livre de valores:

\begin{abstract}
A ideia de que a ciência é livre de valores é mais bem entendida como a combinação de três componentes: a imparcialidade, a neutralidade e a autonomia, e é bem representada pela tese de que três são valores constitutivos das práticas e instituições científicas. A Imparcialidade pressupõe uma distinção entre valores cognitivos e valores sociais, ou seja, valores morais e valores cognitivos de outros tipos; a neutralidade corresponde à não existência de juízos de valor no conjunto de implicações lógicas das teorias científicas (LACEY, 2010, p. 15).
\end{abstract}

Os procedimentos metodológicos foram divididos em três etapas: primeiro com a escolha da base epistemológica oferecida através das aulas de Epistemologia da Ciência, aos alunos do doutorado do Programa de Pós-Graduação em Ensino de Ciências, pela Universidade Federal de Mato Grosso do Sul e também, com o levantamento e coleta do material para a análise das notícias publicadas em jornais, noticiários em sites locais. Na segunda etapa realizou-se a seleção de dados sobre a microrregião de Três Lagoas, momento foi de localização, identificação, saída de campo para observação, registro fotográfico; elaboração e interpretação de mapas e quadro; além da tabulação de dados. Posteriormente, a terceira etapa, seguida pela interpretação e análise dos conteúdos levantados que fundamentaram a escrita desse apontamento sobre uma sociedade distópica a serviço do desenvolvimento econômico sem a preocupação com o meio ambiente.

\section{PLANTIO DE EUCALIPTO E PRODUÇÃO DE CELULOSE EM MUNICÍPIOS DO MATO GROSSO DO} SUL

Segundo dados de Oliveira (2011), o estado de Mato Grosso do Sul está dividido em onze microrregiões, agregando atualmente 79 municípios. A microrregião de Três Lagoas, localizada a leste do estado é constituída pelos municípios de Água Clara, Brasilândia, Ribas do Rio Pardo, Santa Rita do Pardo e Três Lagoas. O clima regional é do tipo AW Tropical, com duas estações bem definidas: uma seca e outra chuvosa. $O$ inverno é extremamente seco, geralmente nos meses de julho a setembro e o verão é o período mais chuvoso (de dezembro a fevereiro).

Aspectos territoriais, hidrográficos e climáticos do estado, aliados ao desenvolvimento tecnológico, propiciam sucesso da silvicultura. Conforme Figura 1, a média anual da temperatura situa-se em torno de $26^{\circ} \mathrm{C}$ e a média anual da precipitação é de 1.300 a $1.900 \mathrm{~mm}$. Assim, em decorrência do clima, a vegetação típica de cerrado é gramínea lenhosa, arbórea densa e arbórea aberta, prevalecendo também na área de estudo. Predominando até a década de 1990 
uma vasta área com pastagem propícia para a criação de gado, mas nas últimas décadas foi sendo substituída pelo reflorestamento de eucalipto.

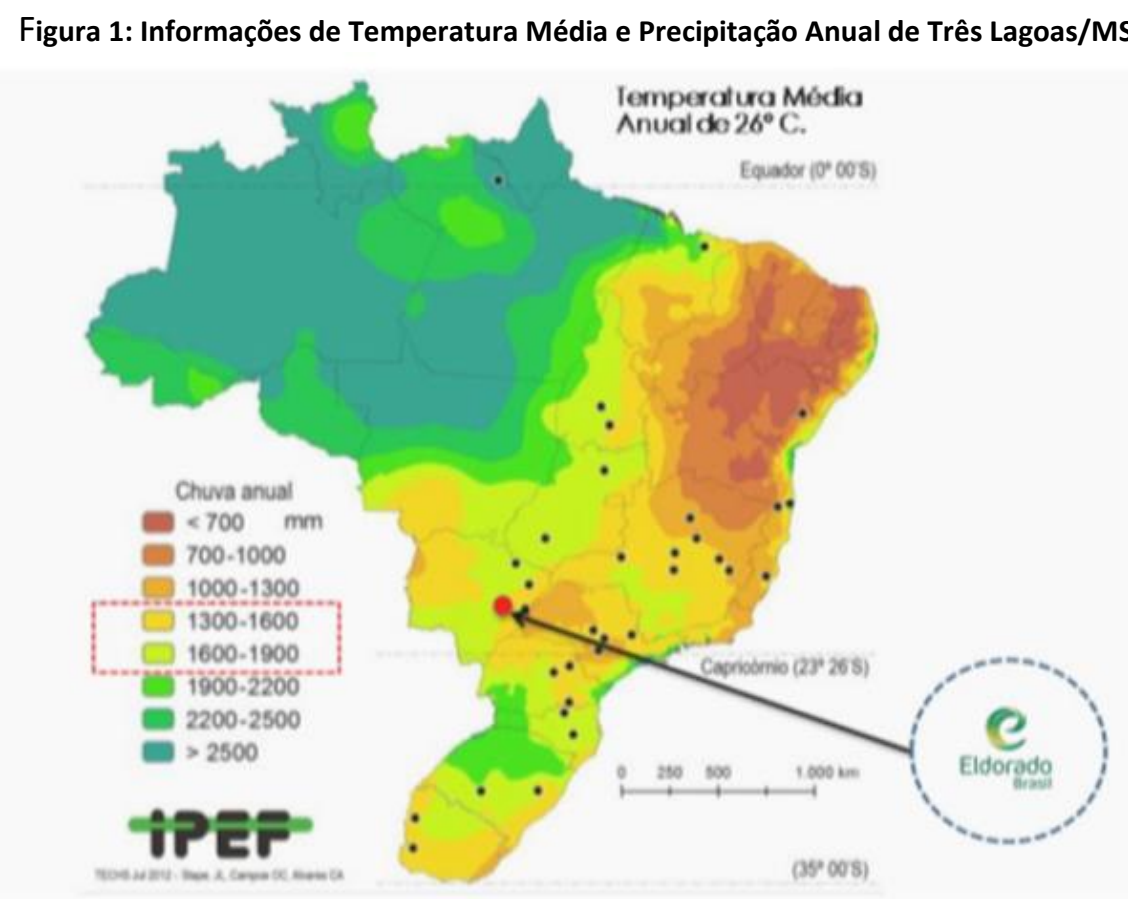

Fonte: ELDORADO, 2017.

O estado de Mato Grosso do Sul, segundo informações recentes de Vitorino (2018), o Estado possui o maior número de municípios, entre os dez maiores em área de florestas plantadas para fins comerciais (silvicultura) no Brasil. A produção cresceu significantemente nos últimos anos, ocupando o terceiro lugar no ranking de área com plantio de eucalipto, somando mais de 1,12 milhão de hectares.

Atualmente os municípios de Três Lagoas, Água Clara e Ribas do Rio Pardo são os três municípios que se destacam na produção de eucalipto. São municípios localizados na porção Leste do estado do Mato Grosso do Sul. Em comum, iniciaram o seu processo de ocupação territorial em decorrência da construção da Estrada de Ferro Noroeste do Brasil, quando foram constituídos os primeiros núcleos urbanos ao redor das Estações Ferroviárias. Importante destacar que o aumento populacional desses municípios teve influência de surtos migratórios de outras regiões (Nordeste, Sudeste e Sul) do país, impulsionados também por atividades econômicas similares (transporte ferroviário, a pecuária e produção de eucalipto). O município de Três Lagoas possuiu atualmente, uma população estimada, segundo o IBGE (2018), de 119.465 habitantes e economicamente encontra-se em $3^{\circ}$ lugar no ranking estadual, logo após Campo Grande com 885.711 habitantes, capital do Estado, e Dourados com 222.949 habitantes. 
Segundo noticiário "O Globo" elencado por KISS (2011), a população três-lagoense rapidamente vivenciou três momentos de crescimento e transformação na economia do município: o primeiro até os anos de 1970 foi marcado pela chegada de colonos aventureiros; o segundo ocorre com o desenvolvimento da pecuária extensiva até a década de 1990; e o terceiro momento ocorre com a substituição de grande parte das áreas de pastagens pelo plantio de eucalipto e consequentemente a produção de celulose.

No ano 2017 o estado registrou um incremento de 30,4\% no valor de produção da silvicultura, superando $\mathrm{R} \$ 1,0$ bilhão e ocupando atualmente a sétima posição entre os estados neste segmento. Nos últimos anos Mato Grosso do Sul ampliou sua participação no setor, ocupando o terceiro lugar na produção de madeira em tora para papel e celulose (KISS, 2011).

Dentre os municípios com maior valor de produção da silvicultura do país, dois municípios sul mato-grossense se destacam com o plantio e produção de celulose, sendo: Três Lagoas, que libera o ranking nacional, seguido por Ribas do Rio Pardo, conforme citação:

Três Lagoas lidera o ranking dos municípios do País com maior valor de produção na silvicultura: R\$ 387,5 milhões somados no ano de 2017. A cidade ainda ocupa o primeiro lugar em áreas de florestas plantadas do Brasil, com 245 mil hectares, seguida de Ribas do Rio Pardo, com 215 mil hectares. Em área plantada, houve aumento de 6,5\% em Três Lagoas no comparativo com 2016. O município encerrou o ano passado com 245 mil hectares, sendo que praticamente $100 \%$ da área é destinada ao plantio de eucalipto. No município de Ribas do Rio Pardo, a área plantada em 2017 somou 215 mil hectares, o que representou incremento de $2,9 \%$ em relação ao ano anterior. Do total, 210 mil são de plantações de eucalipto e apenas cerca de cinco mil são destinados ao plantio de pinus (VITORINO, 2018).

A liderança dos municípios de Três Lagoas e Ribas do Rio Pardo com grandes áreas de plantações de eucalipto e o aumento da produção de celulose para exportação favoreceu a fusão de duas grandes empresas de produção de papel celulose localizadas no município de Três Lagoas. O ano de 2019 iniciou com a fusão da Fibria e Suzano. A fusão foi aprovada pela União Europeia, aumentando a capacidade de produção para 11 milhões de toneladas de celulose, o que significa 1,4 milhões de toneladas por ano (SUZANO, 2019). 
O desenvolvimento econômico do município está ancorado no plantio de eucalipto e na produção de celulose, que desbancou a pecuária extensiva na década de 1990, tendo como objetivo a produção de celulose para exportação. As duas fábricas instaladas no município de Três Lagoas exportam para todo o globo conforme demonstrado na Figura 2. A fábrica Eldorado do Brasil exportava, em 2017, 10\% para os Estados Unidos, 31\% para a Áustria, 43\% para a China e apenas $16 \%$ de sua produção teve destino ao consumo interno no Brasil. A Fábrica Fibria/Suzano exportava, nesse mesmo período, 20\% para a América do Norte, 32\% para a Europa, 39\% para a Ásia e somente $9 \%$ de sua produção foram comercializadas na América Latina.

Figura 2: Distribuição de vendas das Fábricas - Eldorado do Brasil (à esquerda) e Suzano (à direita)

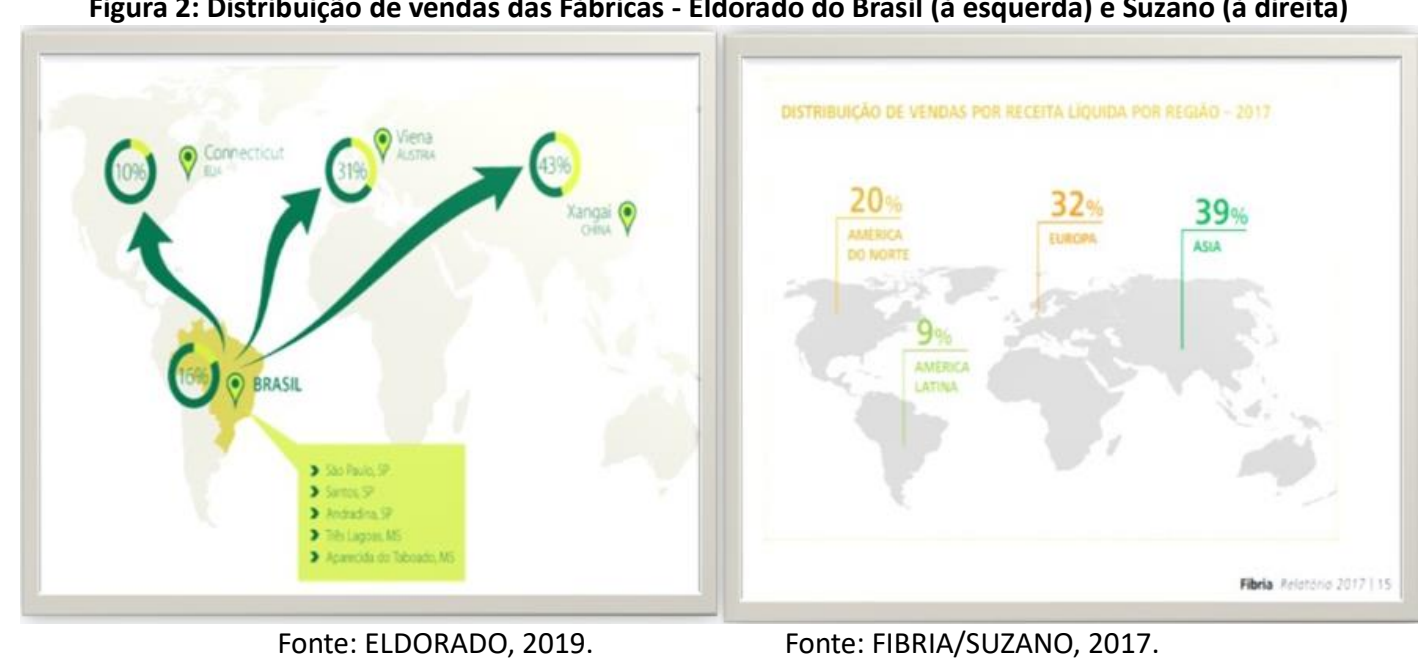

O principal destino dos produtos florestais do Estado de Mato Grosso do Sul é a China, representando cerca de $29,32 \%$ do valor total das exportações. E o maior município exportador foi Três Lagoas, representando cerca de 60\%, nos meses de janeiro de fevereiro de 2019, baseado nas exportações da indústria de Papel e celulose (O PANTANEIRO, 2019).

O modelo de país colonialista, produtor e exportador de produtos primários, prevalece até os dias de hoje. Os moldes desse desenvolvimento, baseado na monocultura, a exemplo do plantio de eucalipto em grandes extensões de terra, têm acelerado os danos ambientais nas áreas ocupadas. Dessa forma, observa-se que é inegável a força política e empresarial sobre os produtos que o país deve produzir para atender às necessidades dos consumidores de outros países.. 
O desenvolvimento e uso de novas tecnologias na clonagem das mudas de plantas maduras, que melhor se adaptam às condições climáticas (chuva e calor) e às condições do solo da região, também revolucionou as novas formas de plantio em tubetes degradáveis que se dissolvem no solo e evitam o uso da super dosagem de adubos. Segundo Flávio Tedesco: “A decomposição do papel é mais rápida e na hora de fazer a expedição para o campo a muda fica mais protegida e fácil de continuar o seu crescimento no solo". As embalagens tradicionais utilizadas no antigo processo eram feitas de plástico, a nova técnica consegue reduzir em média 30 dias no ciclo de produção das mudas por meio do uso desta tecnologia. Segundo a Sociedade de Investigações Florestais, 2014.

Os resultados da pesquisa também revelam que as mudas atingem enraizamento acima da média e redução do ciclo operacional do viveiro, com tempo menor de formação; ganho em produtividade na seleção e expedição, com eliminação da atividade de retirada das embalagens (desentubetamento); ganho em qualidade final com redução do descarte por problemas no sistema radicular e eliminação de perdas ocorridas em campo devido à movimentação das mudas (SIF, 2014).

A técnica começou a ser desenvolvida pela Suzano (antiga Fibria) em 2005 e o projeto inicial foi realizado na Unidade Três Lagoas (MS). Desse modo, o processo tem revolucionado o crescimento e a expansão das áreas de florestas plantadas e consequentemente acelerado o tempo de corte dessa produção, que anteriormente era de 21 anos, passou para 14 anos, depois caiu para 7 anos. Atualmente a planta consegue atingir o tempo de crescimento e de corte em um menor período, em média entre 6 a 5 anos.

O cultivo de eucalipto cresce aceleradamente no Estado de Mato Grosso do Sul, ultimamente ocorre em treze municípios: Água Clara, Anastácio, Aparecida do Taboado, Bataguassu, Brasilândia, Dois Irmãos do Buriti, Inocência, Paranaíba, Ribas do Rio Pardo, Santa Rita do Pardo, Selvíria, Três Lagoas, de modo recente observa-se a expansão de plantio também no município de Campo Grande. Notam-se no mapa (Figura 3) os municípios que atualmente possuem áreas de plantação de eucalipto para abastecer as duas Fábricas de extração e produção de celulose. As fábricas Fibria/Suzano e Eldorado Brasil, ambas localizadas no município de Três Lagoas, vêm investindo muito nas novas tecnologias e automatização das suas linhas de produção do eucalipto, matéria-prima da celulose e energia, através da produção de biomassa. 
Figura 3: Mapa de localização - municípios que cultivam eucalipto no Estado de Mato Grosso do Sul

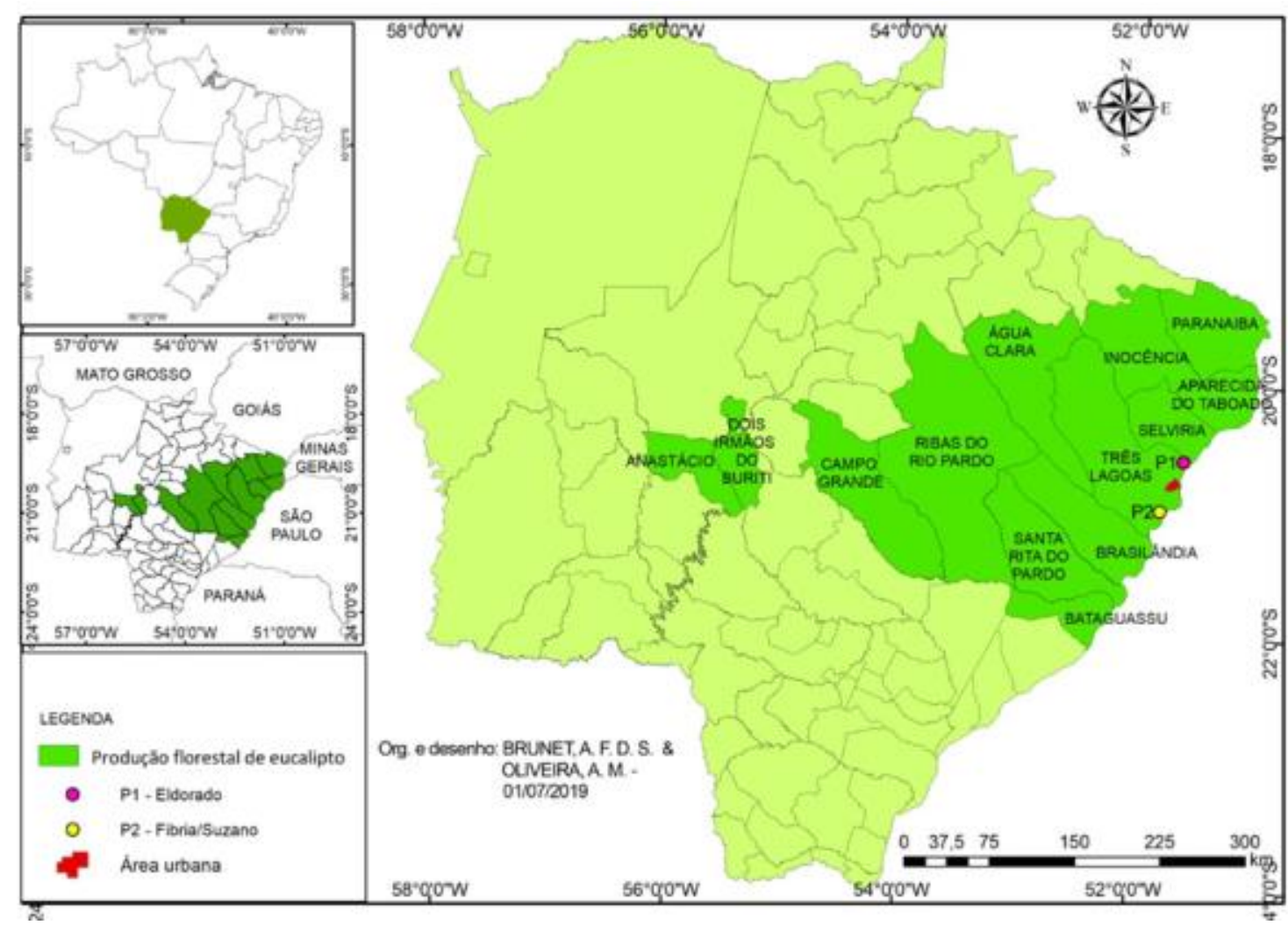

Fonte: BRUNET, A. F. D. S. \& OLIVEIRA, A. M., 2019.

Segundo dados da Eldorado Brasil, no Quadro 1 estão relacionados os municípios que produzem eucalipto e as áreas ocupadas em forma de arrendamento, parceria ou própria, totalizando $359.260,46$ ha. Nota-se que a utilização de arrendamentos equivale a mais de $2 / 3$ das terras ocupadas e que a área de sua propriedade no Brasil é bem menor. Observam-se no quadro 1 os municípios que atualmente possuem áreas de plantação de eucalipto para abastecer especificamente as fábricas de extração de celulose. Em destaque também para a inserção recente do município de Terenos.

Muitos benefícios foram apontados por parte das empresas e administração pública para população três-lagoense. Observa-se que o fator dominante é a geração de renda (economia). A chegada dessa atividade econômica local oportunizaria o reconhecimento internacional das atividades econômicas produzidas pelo município, gerando emprego e renda. Outro argumento seria que o plantio de eucalipto não estaria promovendo a degradação ambiental e sim a recuperação de áreas de pastagens através do reflorestamento dessa espécie. 
Quadro 1: Municípios do Estado de Mato Grosso do Sul - Plantio de Eucalipto - abril /2018

\begin{tabular}{|l|c|c|c|c|}
\hline \multicolumn{1}{|c|}{ MUNICIPIO } & ARRENDAMENTO & PARCERIA & PRÓPRIA & TOTAL \\
\hline Água Clara & $17.660,64$ & $10.170,97$ & & $27.831,61$ \\
\hline Anastácio & 73,95 & $1.815,91$ & & $1.889,86$ \\
\hline Aparecida do Taboado & $20.647,91$ & $3.314,09$ & 958,60 & $24.920,60$ \\
\hline Bataguassu & 501,91 & & & 501,91 \\
\hline Brasilândia & $6.112,66$ & & & $6.112,66$ \\
\hline Dois Irmãos do Buriti & $1.986,04$ & $2.918,63$ & & $4.904,67$ \\
\hline Inocência & $35.618,36$ & $7.912,26$ & $6.397,40$ & $49.928,02$ \\
\hline Paranaíba & $6.939,97$ & & & $6.939,97$ \\
\hline Ribas do Rio Pardo & $16.683,80$ & $7.894,94$ & & $24.578,74$ \\
\hline Santa Rita do Pardo & $19.886,23$ & $18.509,21$ & & $38.395,44$ \\
\hline Selvíria & $50.769,44$ & $20.683,53$ & $6.002,49$ & $77.455,46$ \\
\hline Terenos & 54,32 & & & 54,32 \\
\hline Três Lagoas & $67.092,44$ & $28.654,76$ & & $95.747,20$ \\
\hline TOTAL GERAL & $244.027,67$ & $101.874,30$ & $13.358,49$ & $359.260,46$ \\
\hline
\end{tabular}

Fonte: ELDORADO BRASIL, 2019.

Em alguns jornais locais (on-line) são apresentados alguns dos problemas sociais e ambientais, como o problema de queimadas e incêndios que são preocupações constantes no período de seca e estiagem para os silvicultores e para os proprietários de fábricas de celulose que possuem milhares de hectares plantados em Três Lagoas. As queimadas causam prejuízos não só econômicos, mas ambientais e sociais (OJEDA; ANDRADE, 2017).

O impacto causado pelas queimadas é maior do que apenas um pedaço de terra. o impacto é ambiental, com a perda da biodiversidade existente no local, degradação do solo e emissão de gases. Os impactos sociais recaem sobre a esfera da saúde, com o aumento de problemas respiratórios e, em alguns casos, a mudança de local que algumas famílias são obrigadas a ter. A economia também é afetada, se levar em consideração que rodovias e estradas muitas vezes acabam sendo fechadas devido à fumaça, além de aeroportos e a destruição de plantações e a morte de rebanhos (OJEDA; ANDRADE, 2017).

Os valores e preocupações divergem conforme o ponto de vista. Para o engenheiro florestal e diretor de relacionamento internacional da Associação Brasileira Técnica de celulose e Papel (ABTCP), o plantio de eucalipto é sinônimo de sustentabilidade; ainda segundo o engenheiro, as empresas cumprem as normas de manejo florestal, como o estudo da topografia da região e a projeção de corredores para os animais circularem (VIEGAS, 2018). E, por outro lado, observase que é uma utopia acreditar nesse modelo de produção econômica que prioriza a lucratividade sem mensurar os verdadeiros impactos ambientais e a extinção da biodiversidade.

Os benefícios econômicos são facilmente projetados nos meios de comunicação para divulgação do município. Porém, consoante Fonseca (2014), os impactos sociais e ambientais causados com 
as atividades econômicas não são noticiados pela mídia, como: o aumento da violência; de acidentes no trânsito local e rodoviário; insuficiência nos serviços de moradia, educação e atendimento na área da saúde; degradação do solo; poluição do ar e comprometimento na biodiversidade da fauna e flora; além de tantos outros problemas que vêm ocorrendo, tanto na área urbana quanto na área rural.

A ideia de ciência produzida para o desenvolvimento tecnológico e bem-estar social, segundo Lacey (2010), deve ser analisada a partir de três pressupostos: a imparcialidade, a neutralidade e a autonomia. Para o epistemólogo, a imparcialidade pode ser realizável (factível), a neutralidade estará influenciada pelo pluralismo metodológico e a autonomia não é realizável, haja vista que a ciência precisa ser financiada e a autonomia está vinculada ao provedor.

Ao percorrer a BR-262 de acesso aos municípios de Três Lagoas, Água Clara, Ribas do Rio Pardo e Campo Grande, por mais de 320 km, fica evidente a dimensão do avanço das plantações de eucalipto, além de observar os contrastes nas paisagens, ora com a presença do cerrado, em outros, com poucos registros da presença do gado, com restritas áreas de pastagens destinadas à pecuária extensiva; o que se destaca mesmo são as produções de eucalipto.

Atualmente é comum encontrar as placas com identificação dos hortos dessas produções, nas porteiras das fazendas, onde anteriormente localizavam os grandes produtores do gado de corte do Estado/MS. Assim, as grandes áreas de plantio de eucalipto bem próximas das BR são lugares com pouca presença da diversidade de espécies da fauna e da flora do cerrado. Os troncos retorcidos e de pequeno e médio porte das espécies nativas do cerrado diferem radicalmente de um padrão reto de dimensão alta do eucalipto, essas imagens falam por si mesmas, mostrando que as áreas marginais da rodovia contrastam as características do Cerrado brasileiro com domínio da produção de eucalipto de origem estrangeira.

O plantio de eucalipto no município de Três Lagoas expandiu (Figura 4) e estabeleceram-se em terras boas, baratas e mecanizáveis, porém, teve maior êxito com a mudança genética, cuidados com o solo, técnicas de plantio e irrigação, fruto de investimentos em pesquisas. 
Figura 4: Atividades Econômicas no município de Três Lagoas/MS.

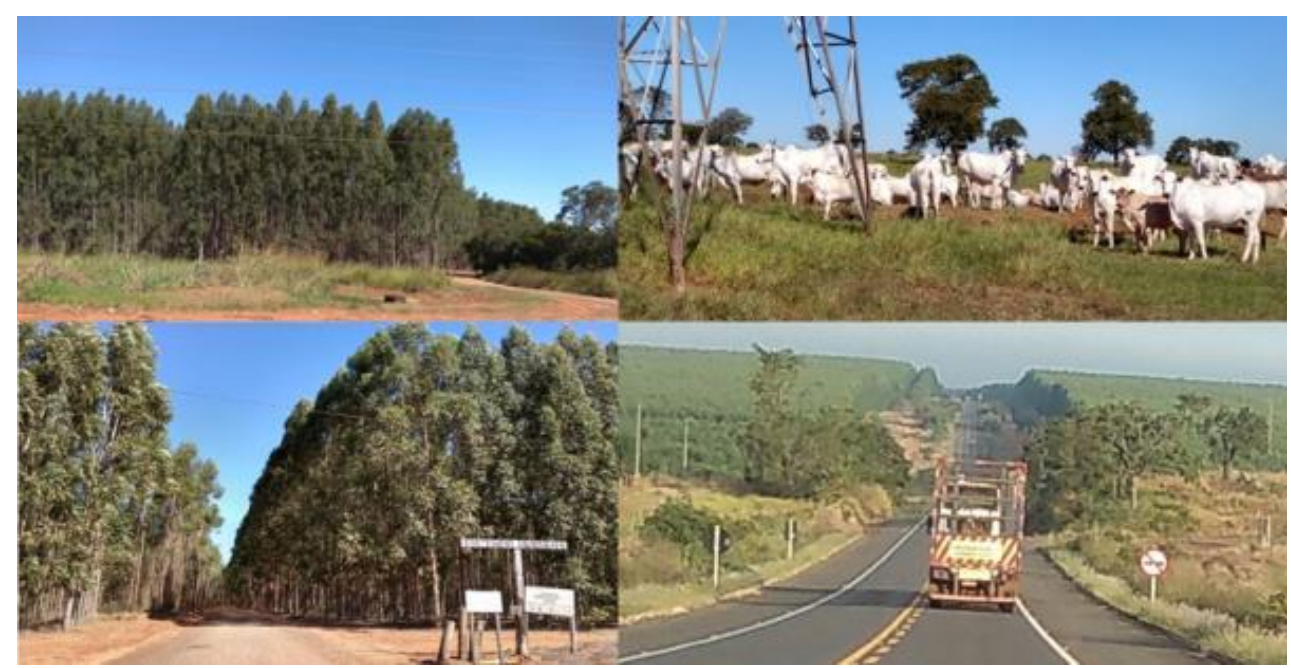

Fonte: OLIVEIRA, A. M. 2019.

É sempre um grande desafio para os motoristas e passageiros viajar pela BR - 262, no trajeto que liga os municípios de Três Lagoas à capital do Estado (Campo Grande), muitas vezes é um motivo de apreensão e tensão para os parentes que esperam pela chegada de seus familiares. A estrada ficou conhecida como "rodovia da morte", além de estar em péssimas condições, repleta de buracos, não possui acostamento na maioria do seu percurso.

O grande número de carretas que circulam diariamente nessa rodovia, transportando madeira cortada/eucalipto para as duas fábricas de produção de celulose, torna a rodovia mais tensa e perigosa, indiretamente colaboram com o aumento do número de acidentes (Figura 5).

Figura 5: Colheita e transporte de eucalipto

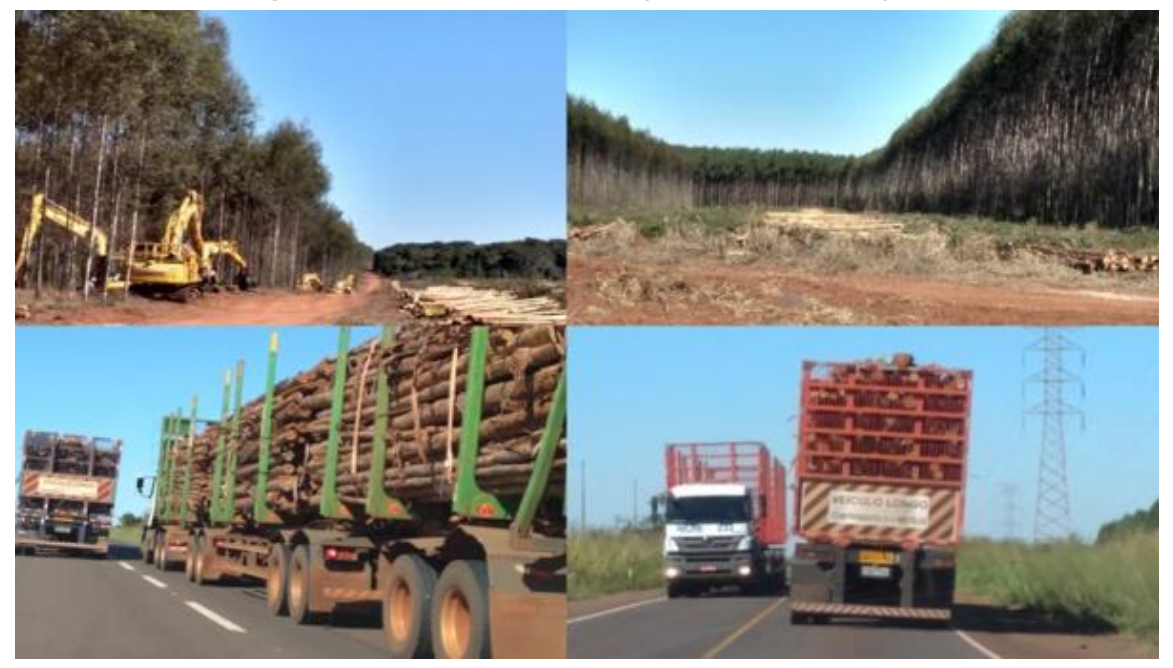

Fonte: OLIVEIRA, A. M. 2019. 
Visando ampliar sua produção e seus lucros, as fábricas vêm investindo cada vez mais em tecnologias. A Fibria ampliou sua linha de produção de celulose em Três Lagoas/MS e investiu em novos equipamentos de corte e colheita da madeira:

Com a melhor performance no mercado: as máquinas Harvesters (HV) e Forwarders (FW). Utilizadas para realizar a colheita de madeira sem casca, elas não só vão garantir o abastecimento do Projeto Horizonte 2, como irão possibilitar custos de produção bastante competitivos. Ambas possuem cabines equipadas com ar condicionado e os melhores padrões de conforto e de segurança para os profissionais da companhia (ASCOM, 2017).

Segundo noticiário local (ASCOM, 2017), uma operação padrão do Harvester produzia (aproximadamente) $25 \mathrm{~m}^{3}$ de toras por hora, enquanto o novo equipamento da Forwarder ampliou sua produção para aproximadamente $62 \mathrm{~m}^{3}$ por hora. Portanto, com a adoção desse sistema operacional computadorizado dos equipamentos, que mede e indica a produção e todos os dados operacionais relevantes, como comprimento das toras, diâmetro, pressões, temperaturas, entre outros, essa produtividade, em um curto período de seis anos, consegue reduzir sistematicamente o custo unitário de colheita (custo para produzir $1 \mathrm{~m}^{3}$ ), contribuindo para o aumento de competitividade global da Fibria/Suzano.

O desenvolvimento científico, segundo Lacey (2010), precisa observar o contexto social, ecológico e humano, não olhando a natureza apenas como fonte de matéria-prima. $\mathrm{O}$ autor ressalta que a ciência tem sido utilizada como um negócio, visando lucratividade.

Os valores epistêmicos e/ou cognitivos pontuados por Lacey (2010) estão relacionados à avaliação cognitiva, como detentora de conhecimento e entendimento dos fenômenos. Todavia, os valores sociais e éticos podem assumir vários papéis de que uma sociedade deseja, como por exemplo: progresso, justiça social e comportamento humano. $\mathrm{O}$ autor pontua que a ciência tem que fazer a distinção entre os valores cognitivos dos sociais e éticos, salientando a imparcialidade.

\section{CONCLUSÃO}

O Município de Três Lagoas, localizado na porção Leste do estado de Mato Grosso do Sul, nas últimas décadas apresentou um grande crescimento econômico, baseado inicialmente na pecuária extensiva e depois no plantio de eucalipto e produção de celulose, colocando-o no cenário nacional de economia.

As alterações ambientais causadas pelas atividades econômicas, quase não são mensurados pelos meios de comunicação. Apenas os problemas causados no meio ambiente, como queimadas, que ocasionam doenças respiratórias, são noticiados nos jornais locais.

Observou-se que a construção do conhecimento científico se apresenta (em geral) de forma imparcial, porém, a aplicabilidade da ciência não consegue ser livre de valores. Ainda é muito forte na sociedade a concepção de ganhos econômicos, sem a preocupação com o meio ambiente.

Observa-se que a plantação de eucalipto nessas áreas serve principalmente como fonte de matéria-prima para produção de celulose e fabricação de papel, com o propósito de abastecer o 
mercado externo. Exportando para países como a China, os Estados Unidos e a União Europeia. Assim, menos de $15 \%$ da produção permanece no Brasil para atender o mercado interno e população brasileira.

Dessa forma, os avanços tecnológicos estão apresentados nesse estudo em duas vertentes: a do desenvolvimento econômico, expressamente vital pela sociedade, e a de controle de recursos naturais, isto é, o uso da natureza como fonte de matéria-prima, sem mensurar os danos ambientais. Nesse contexto, ficou evidente a dicotomia entre esses diferentes cenários: econômico, social e ambiental. Desrespeitando a compreensão de valores concebidos, seja pessoal, moral ou sociais apontados nesse estudo sobre o ideal processo de desenvolvimento econômico ou científico.

Nota-se certo descaso com as questões ambientais, como: a extinção da biodiversidade com a retirada das espécies nativas e com o falso reflorestamento (silvicultura), que abriga pouca ou quase nenhuma espécie da biodiversidade do cerrado. Os problemas e impactos socioambientais dificilmente são expostos e ou discutidos em sociedade.

A plantação de eucalipto prioriza atender as necessidades e anseios econômicos, em favorecimento da produção industrial, do lucro, porém, falha em promover a conscientização ambiental em detrimento de promessas de melhorias do poder aquisitivo da população local.

\section{REFERÊNCIAS BIBLIOGRÁFICAS}

ASCOM. Máquinas de colheita florestal reduzem custos e aumentam a competitividade de fábrica em Três Lagoas Rádio Caçula, 2017. Disponível em: www.radiocacula.com.br/noticias/economia/maquinas-de-colheita-florestalreduzem-custos-e-aumentam-a-competitividade-de-fabrica-em-tl. Acesso em: 05 jul. 2019.

ELDORADO BRASIL Nossa Celulose no Mundo. Site Institucional, 2019. Disponível em:

http://www.eldoradobrasil.com.br/Institucional/QuemSomos/Localizacao-Global9. Acesso em: 03/05/2019.

FIBRIA-SUZANO, Redação. Site Institucional, 2017. Disponível em: https://www.celuloseonline.com.br/segundafabrica-da-fibria/. Acesso em: 05/05/2019.

FONSECA, S.R. A Consolidação do Complexo de Celulose e Papel na Região Leste de Mato Grosso do Sul. Revista Eletrônica da Associação dos Geógrafos Brasileiros, 2014.

IBGE. Cidades. Disponível em: https://cidades.ibge.gov.br/brasil/ms/tres-lagoas/panorama. Acesso em: 01/05/2019.

KISS, Janice. Plantações de eucalipto desbancam pecuária de corte em Mato Grosso do Sul. Revista Globo Rural, 2011. Disponível em: http://revistagloborural.globo.com/Revista/Common/. Acesso em: 03/05/2019.

LACEY, Hugh. Valores e Atividade Científica 2. São Paulo: Associação Filosófica 'Scientiae Studia'/Editora 34, 2010.

VITORINO, Paula. Portal do Governo do Mato Grosso do Sul. IBGE mostra que município de MS libera área plantada e valor em produção de silvicultura. Cuiabá: Governo do Estado, 2018. Disponível em: http://www.ms.gov.br/ibgemostra-que-municipios-de-ms-lideram-area-plantada-e-valor-em-producao-de-silvicultura/. Acesso em 03/05/2019

MORAES, Roque. Análise de conteúdo. Revista Educação, Porto Alegre, v. 22, n. 37, p. 7-32, 1999.

O PANTANEIRO. Com aumento expressivo da produção de celulose, eucalipto passa a contribuir com Fundersul. Edição Digital do Jornal “O Pantaneiro”, 2019. Disponível em: http://www.opantaneiro.com.br/economia/com-aumentoexpressivo-da-producao-de-celulose-eucalipto-passa-a/146761/. Acesso em: 03/05/2019. 
OJEDA, Ricardo; ANDRADE, Ygor. Queimadas preocupam gigantes da celulose em Três Lagoas, que investem pesado em tecnologia. Perfil News, 2017. Disponível em: www.perfilnews.com.br/queimadas-preocupam-gigantes-dacelulose-em-tres-lagoas-que-investem-pesado-em-tecnologia. Acesso em: 12 maio de 2019.

OLIVEIRA, Arlinda Montalvão de. Estrada de Ferro Noroeste do Brasil. Dinâmica socioespacial e territorial em MS. Campo Grande: FCMS; Life Editora, 2011.

RIZÉRIO, Lara. Nasce uma gigante: após começo de ano sem brilho, fusão Suzano e Fibria pode impulsionar ações na Bolsa? Info Money, 2019. Disponível em: www.infomoney.com.br. Acesso em: 10 maio 2019.

SIF, Sociedade de Investigações Florestais. Fibria desenvolve tecnologia para a produção e plantio de eucalipto. Notícias. SIF, 2014. Disponível em: www.sif.org.br/noticia/fibria-desenvolve-nova-tecnologia-para-o-plantio-deeucalipto. Acesso em: 01 jun. 2019.

VIEGAS, Anderson Viegas. Referência na pecuária brasileira, MS ganha centro de formação que vai capacitar profissionais para todo o país. G1 MS, 2018. Disponível em: https://g1.globo.com/ms/mato-grosso-dosul/noticia/referencia-na-pecuaria-brasileira-ms-ganha-centro-de-formacao-que-vai-capacitar-profissionais-paratodo-o-pais.ghtml. Acesso em: 08/05/2019. 